\title{
Leprosy Control Project Plan \& Its Achievements
}

\author{
By Dr. I. B. Mali - Chief of the Project
}

\section{INTRODUCTION:-}

It is a well established fact to-day that leprosy in the least infectitions disease; that it can be diagnosed early; that it can be successfully treated and that the patients affected with leprosy can lead a normal community life while undergoing treatment. It took more than a decade for Nepal to take Cogrizance of the great achievement in medical research. Nepal is going slowly but smoothly with success to wipe out the traditional supertition and quasi-religious ideas prevalant with the mass here -- a revolutionary step. when compared with some other contries.

\section{PURPOSE :-}

The purpose of this paper is to present the Plan of operation and the achievements so far in integrating leprosy in the general health serious of the country. As the 5th Five year Plan is hearing, this paper will also touch upon some highlights of the future plan with the hope that all case will have the right attitude of the disease.

\section{Background :-}

The project is sending out to different regions of the country to give health education first to the elites than to the patients and their relations and later to the people in the areas immediately surrounding the existing health posts. Tbis is better known as mobile team of S. E. T. as it moves on from place to place. Henceforth it will be refirred 
as S. E.T. mobile team in this paper.

The result obtained so far in deciding the prevalance rate of leprosy in Nepal varies from 10 per mille to under 5 per mille in others. Hence a target to becommitted in the Plan in terns of total number of cases to be detected is not realistic at present. But one thing that the project has found out that $75 \%$ to $80 \%$ of leprosy patients in Nepa] are noninfections.

Another experience obtained is very significant. There are THREE TELL - TALE facts :-

1. In terms of cast benifit analysis, it is ten times cheaper to give domicidials: treatment as compared to institutional treatment.

2. In terms of social gain, when leprosy treatment is integrated in general health serious, there is no social injury whatsoever.

3. Leprosy Control Project does no longer like to harp on the same old shing of ostracism.

With there above flodings leprosy Control Project has the policy of putting a fence at the lip of the precipie rather than at the bottom i.e. detection of early cases and giving a stitch in time. For the intersent of readers, the later part of the paper will present how the country is going to solve the problem of advanced cases of the disease.

\section{OVERALL PLAN OF OPERATION:}

There are two phases of leprosy Control :-
a) THE ATTACK PHASE
b) THE MAINTENANCE PHASE

The Attack Phase is carried out by S. E.T. mobile team consisting of twenty one paramedical workers spreading education on the understanding of the modern concept of heprology to all concerned as mentioned earlier. It will survey the school children and will also do mass survey in selected village where village headmen report cases of leprosy. The area of survey will be concerntrated only within three miles radii of the health units. The moment the patient is found out, he or she will be brought to the health unit where complete clinical examination including skiñ smeats will be done to make the diagnotis. When once the diagnosis is confirmed, treatment will be started. The clinical examination, and treatment part of the work is done in conjunction with the bealch personnels of the healtb unit there. Thus the healtb staff learns enough to handle leprosy cases. 


\section{THE MAINTENANCE PHASE:-}

When once the SET rrobile team hands over the patients to the health unit, it is called Maintence Phase. Before handing over the cases. the mobile team will give a full understanding of leprosy to the health worded and also provide them with booklets on leprosy and treatment cards in the required medicines explaining them. how to continue the treatment,

\section{AIMS in the Head Quarters :-}

With the above background let us how see the aims of the Head-quarters of the Project.

1. It airns to have a strong referral centre in the Head-quarters.

2. A nucleus of full-time health workers SET mobile team to the trained to carry on the conttol work.

3. In 3 months training in the beginning and time to time regular refreshers course of inservice training to be given to leprosy workers.

4. Health schools, nursing schools and others are always to be welcomed when teaching leprology is requested.

5. In the time short course of training to be carried out in different places calling doctors from various zones or districts.

6. Recording and reporing of cases on treatment activities are to be maintaiaed in a well designed standard form and a control Register is to be maintained.

7. Attempts to repeal or modify the legislation on leprosy are to be pursued.

8. A regular supervision of the field work is to be carried out from Head-quarters.

9. The international agencies and local voluntary organization concerned with leprosy work in Nepa! are to be guided properly so that there will be no duplication of efforts.

10. All vertical projects under HMG/Nepal are to be well informed on the policy, aims, plan of operation so that, when necessary and when found feasible, leprosy Project will work hand in hand.

11. Correcting the Control measures continuously so that the campaign suits most to the local needs, thinking that the control measures should not be inflexible. 


\section{TARGET:-}

The SET mobile team consisting of 21 workers coners in one year cne Zone which on an average has four hospitals, three health centres and twenty-six bealthposts. The target set for the population to be survoyed is normally about $1,25,000$.

\section{FINANCE:-}

It is obviousily not possible to omit to mention finantial involuement of the project in a paper like this. On an average the annual expenditure of the Project during the last 5 years is Rs. $1,37,900$ N.C.

\section{ACHIEVEMENT:-}

So far the [Leprosy [Control Project has covered the middle and eastern regions of Nepal. None this year it is working in the Lumbini Zone of Western Region. The achieve.: ments made so far is shown in TABLE I. (Please see on Page No. 103 ).

\section{DISCUSSION ON TABLE I:-}

1. The carnot but wouder to see the grcat grief if difference of the number of patients receiving treatment none 14,273 in 7 zones from 925 in the whole of Nepal before the establishment of the Project.

2. Prevalance Rate of leprosy in Nepal varies from 5 to 17 so far worked out.

3. There are at present 227 hoalth units in the seven zones but in 118 only integrated leprosy work was done. The left behind 109 health units were opened after the mobile ieam had left the area.

4. Narayani Zone has $11,03,027$ population. It has 5 districts. The total number of patients found out by the SET mobile toam in the whole Zone was 306 and number of population was 1,27,730. In all the districts of the zone. In Bara districts with population of $2.33,401$ the total number of patients found out was 81 and it bad 3 health units. This is the history of the year 1969 A.D. In the year 1973 A.D. Department of Health services focussed its attention in the district of Bara by opening 9 more health posts making the total number 11 Due attention was given to make their health post efficient. None after 2 years of having 11 health post in that particular district, the number of patients besides 81 on regular treatment is 1020 making the total no. 1101. That means a rise: 


\begin{tabular}{|c|c|c|c|c|c|c|}
\hline \multirow{2}{*}{\multicolumn{2}{|c|}{ 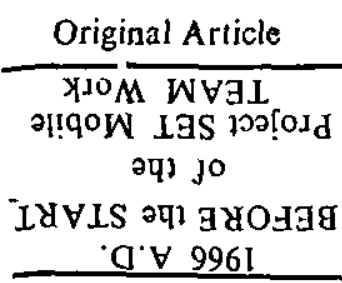 }} & \multicolumn{4}{|c|}{ VOL. 13 NO. $5 \& 6,40$ th Issue } & 103 \\
\hline & & & 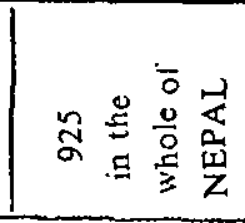 & & & \multirow{10}{*}{ 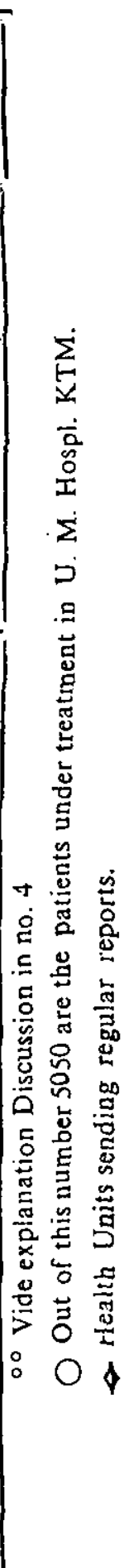 } \\
\hline & TVIOL & 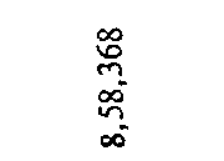 & 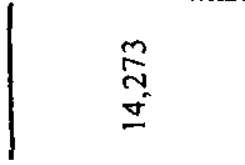 & $\equiv$ & $\stackrel{ }{=}$ & \\
\hline & $\begin{array}{c}S L \nabla L 6 \mathrm{l} \\
\text { aNOZ } \\
\text { INIGผกT }\end{array}$ & 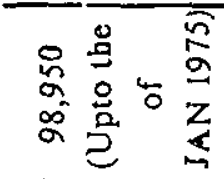 & 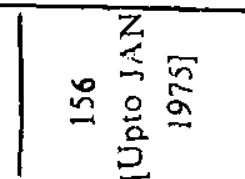 & 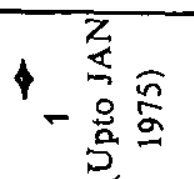 & 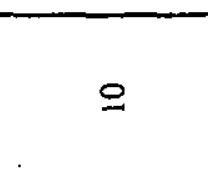 & \\
\hline$\frac{1}{4}$ & $\begin{array}{r}D L-\varepsilon L 6 \mathrm{I} \\
\text { JNOZ } \\
\text { HOJW }\end{array}$ & $\begin{array}{l}n \\
m \\
m\end{array}$ & 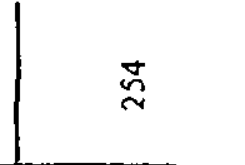 & $\simeq^{4}-$ & $\neg$ & \\
\hline$\overbrace{a}^{n}$ & $\begin{array}{r}\varepsilon L-Z L 6 I \\
\text { JNOZ } \\
\text { IHSOX }\end{array}$ & $\begin{array}{l}\stackrel{0}{N} \\
\text { mi } \\
\\
=\end{array}$ & $\bar{n}$ & $\hat{\sim}_{m}$ & 요 & \\
\hline- & $\begin{array}{c} \\
Z L-|\angle 6| \\
\exists N O Z \forall H \perp \\
-\forall W \& V D V S\end{array}$ & 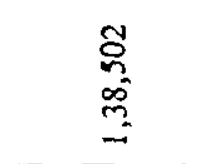 & 手 & $\cong m$ & $\stackrel{\sim}{\sim}$ & \\
\hline$\frac{0}{\pi}$ & $\begin{array}{c}1 L-0 L 6 \mathrm{I} \\
3 N O Z \\
\text { G } 20 \mathrm{X} \forall N \forall \mathrm{C}\end{array}$ & $\begin{array}{l}\mathscr{8} \\
\delta \\
0 \\
=\end{array}$ & ga & $=4+$ & 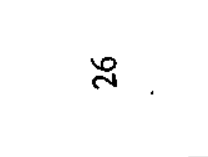 & \\
\hline & $\begin{array}{c}0 L-6961 \\
\exists N O Z \\
\text { IN } \forall X \forall Y \forall N\end{array}$ & 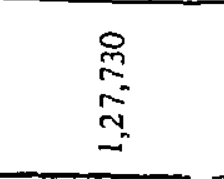 & 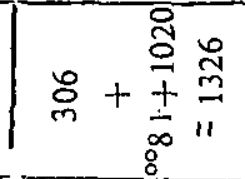 & $a^{4} n$ & $\bar{\sim}$ & \\
\hline & $\begin{array}{c}69-8961 \\
\text { उNOZ } \\
\text { ILVWDVg }\end{array}$ & $\begin{array}{l}\tilde{g} \\
\stackrel{-}{8} \\
\text { j. }\end{array}$ & 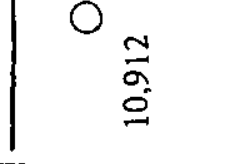 & $=^{4}=$ & 9 & \\
\hline & & 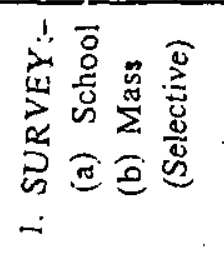 & 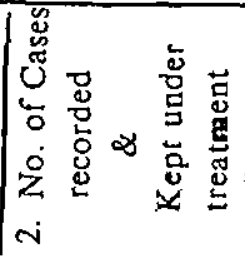 & 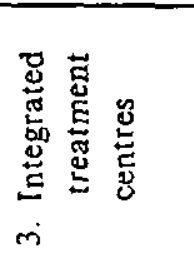 & 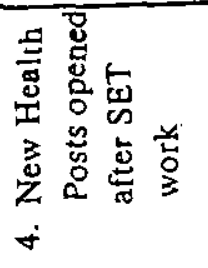 & \\
\hline
\end{tabular}


of 1020 case without any survey.

CORRECTIONS to be made for the future work procedure. (It will indirectly touc upon the bighlights of the Plan proposed for the 5tb Five year also.)

1. Health Education is an intrinsic part of the Plan. This programme will carried out in every panchayat and every scbool of the country. The project strongly believes that person to person contact in the most successful type Health education. A few words from the month of a curad person is like a gospe to our country men.

2. The Project will do survey only in the immediate vicinity of the health unit a hefore.

3. The target will be defined in terms of the number of Panchayats and school to be covered and also of the number of health units to be covered but neve in terms of population to be surveyed.

4. To minimise the effort and to same the double expenditure its case finding and also health education on it will also be done by the same SET mobile teanit The future plan has already been wisely discussed with the chief of its centrat Projeet.

Before coming to the summary of the paper, let us see the problem and solution of the other side of the coin. It is estimated that $30 \%$ of the total number of leprosy patients across the country have a!ready developed this or that sort of deformity.

$25 \%$ of them do not need rehabilitation. Now comes the question of $5 \%$ Most them can be re-eslablished in their village home by small grast of land, house repair live stocked. Each of them needs ancouragement, training, motivation and subsequent super vision. Each of them needs careful assessment and a small grant. So the man will be able tố live on bis own. feet. Finally the question of the remaining precipitate of there $5 \%$ comes This can better be answered by the Plan submitted for the Sth Five Year Plan period. During this plan period 850 palients are ready for rehabilitation and they should be established on a farming land. 500 patients need "Home for the Crippled". The Plan also envisaqes room to be planned for more accomodation which is estimated not to increase by more than 5000 patiens accross the country in the proportion of 1 is to 1.7 as "Home for Cri ppled' to 'Farming land for Rehabulitation.'

\section{Summary:-}

This paper has emphasised the problems, programmes of the Leprosy Controj 
Project encluding the future correction made on the basis of past experience, In summary the whole work of the control can be saiu as "Priming the pump". "It reminds the writer the significant mills of great newspaper chain, "Give light and perple will find their way".

\section{Conclusion:-}

Leprosy Control Project is to eradicate the of the disease so that in the long run there will be reduction of endemicity. Emphasis has been laid upon domicialiary treatment. No progress can de made in the reduction until the patients are encouraged to seek treatment and this can only be successful if treatment facilities are provided at every bealth units of the country. The disease is prevalent in Nepal and the general practitioner including doctors and healthworkers are bound to come across case of leprosy depending on the frequency of the endemicity of the disease in the particular area. As fact Leprosy Control Project appeals to all of them here in Nepal at least to recognise cases and to institute early treatment and to others all concerened to have the right attitude of the disease. 